Research Article

\title{
Seismic Behavior of Reinforced Concrete Frame Joints in Coastal Atmosphere
}

\author{
Chen Cao, ${ }^{1}$ Shan-suo Zheng $\mathbb{D}^{1,2}$ Wei-bing $\mathrm{Hu} \mathbb{D}^{1,},{ }^{1,2}$ Li-guo Dong, ${ }^{1}$ and Xiao-rui Liu ${ }^{1}$ \\ ${ }^{1}$ School of Civil Engineering, Xi'an University of Architecture and Technology, Xi'an 710055, China \\ ${ }^{2}$ Key Lab of Structural Engineering and Earthquake Resistance, Ministry of Education (XAUAT), Xi'an 710055, China \\ Correspondence should be addressed to Wei-bing Hu; wbh8008@sohu.com
}

Received 25 August 2019; Accepted 12 December 2019; Published 10 March 2020

Academic Editor: Emanuele Brunesi

Copyright (c) 2020 Chen Cao et al. This is an open access article distributed under the Creative Commons Attribution License, which permits unrestricted use, distribution, and reproduction in any medium, provided the original work is properly cited.

The study aims to research the influence of salt fog corrosion cycles on seismic performance of reinforced concrete (RC) frame beam-column joints in coastal atmosphere. Based on low cyclic loading tests of six RC frame beam-column joint specimens, this study analyses the failure patterns, hysteresis loops, load carrying capacity, displacement, backbone curves, and energy dissipation capacity of corrosion-damaged RC frame beam-column joints. The effect of salt fog corrosion cycles and axial compression ratios are tested repeatedly. The results show that with the same level of axial compression of the frame joint specimens, as the increase of salt fog cycles, the strength, ductility, energy dissipation, bearing capacity, and deformation capacity of joints degenerated to different degrees. When the corrosion level is the same, the stiffness degradation appeared to be more apparent as the increase of axial compression ratio. Then, the behavior degeneration rule of the RC frame beam-column joints is analyzed and formed according to the results of the test; the degeneration restoring force models of corroded RC frame beam-column joints is formed and verified based on Clough's three-line degenerate restoring force model and the introduction to cyclic degeneration index. The results show that the restoring force model can better describe the hysteresis characteristics of the beam-column joints of corroded $\mathrm{RC}$ frames. The research is a theoretical reference for the seismic analysis of the RC frame structure affected by coastal atmospheric environment.

\section{Introduction}

Reinforcement corrosion is the main cause of deterioration of RC structures $[1,2]$. Longitudinal reinforcement corrosion will result in the decrease of effective cross-sectional area, the degradation of mechanical properties, and weakening the bond performance between the steel bar and the concrete [3]. Stirrups corrosion will reduce the restraint on the core concrete [4], which will deteriorate the performance of RC structures [5]. Because of the higher level of air humidity and chloride ion, the steel cumulative mass loss rate in coastal atmosphere is faster than that in the general atmosphere. As a result, chloride ion erosion is the main cause of steel bars corrosion in coastal atmosphere [6]. Moreover, China is a country with a long coastline and frequent earthquakes, and RC structures in coastal atmosphere are located in the earthquake regions as well. Therefore, it is necessary to study the effect of chloride ion ingress on the seismic performance of RC structures in coastal atmosphere.

Currently, domestic and foreign scholars have conducted extensive researches on the deterioration of the seismic performance of corroded RC structures. $\mathrm{Ou}$ and Nguyen $[7,8]$ have experimented the seismic performance of corroded reinforced concrete beams. It showed that corrosion in longitudinal tension reinforcement had significant detrimental effects on the yield drift, yield load, and peak load [7]. The corrosion of hoops adversely affected the deformation capacity of the beams significantly yet did not significantly influence the load-carrying capacity of the beams [8]. Zheng et al. [9] experimented on the seismic behaviors of corroded RC frame beams, which failed in flexure-shear mode under the artificial climate. It showed that the ductility, bearing capacity, stiffness, and hysteretic energy of the specimens gradually decreased with the increase of the corrosion degree of steel bars. The failure mode 
would transit from flexure-shear failure to shear failure. Ou et al. [10] studied the performance of a large proportion of corroded RC beams subjected to cyclic loading. The experimental results were similar to those of Zheng et al. [9]. A group of studies have researched the influence of the corrosion degrees and the axial compression ratios on the seismic performance of RC columns [11-14]. Zheng et al. [11] indicated that the bearing capacity, deformation capacity, and energy dissipation capacity of the specimens decreased as the steel corrosion increases.

Gan et al. [15] proposed a joint system that connected the thin-walled square reinforced concrete-filled steel tube (RCFST) column to RC beams at both sides of the joint. Zhou et al. [16] conducted the cyclic test of square-tubed reinforced concrete column to the RC beam joints and studied the seismic performance of the joints. Kanchanadevi and Ramanjaneyulu [17] investigated the seismic response of corrosion-damaged beam-column subassemblages. The results showed that the corroded specimens displayed poor hysteretic performance in the form of huge in-cyclic strength degradation. Yang et al. [18] conducted the cyclic tests of ten corroded beam-column joints of SCOPE system, and the studies indicated that corrosion of steel bars significantly affected seismic behaviors of the structure. From the above studies, the research on seismic performance on corroded concrete structures mainly focused on flexural and compressive members, and the RC frame joint specimens were still less. It should be noted that most research works used electrochemical methods to accelerate the steel corrosion $[7,8,12-14,19,20]$, while Yuan et al. [21] and Zhang et al. [22] indicated that the corrosion mechanism and the surface characteristics of steel bars after corrosion under the condition of electricity were obviously different from those under natural conditions, but the artificial weather environment to accelerate corrosion was basically the same as natural environment corrosion. Artificial climate environment simulation technology is an important way to develop durability testing methods for RC structural members [21].

This study adopts the artificial climate environment accelerating corrosion technology (salt spray corrosion test) to simulate the coastal atmospheric environment to conduct the accelerated corrosion test of six RC frame beam-column joint specimens and the pseudo-static tests in order to research the influence of the steel corrosion degree and the axial compression ratio $n\left(n=N / f_{c} b_{c} h_{c}\right.$, where $N$ is the axial force, $f_{c}$ is the concrete compressive strength, and $b_{c}$ and $h_{c}$ are the concrete column section width and height, respectively) on the seismic behavior of the RC frame beam-column joints.

In recent years, a lot of research works have been carried out on the restoring force models of structures at home and abroad. The typical restoring force models include Clough and Johnston degenerate bilinear model [23], Ramberg-Osgood restoring force model [24], Takeda degenerate three-line model [25], Bouc and Wen restoring force model $[26,27]$, etc. However, these studies are based on the intact specimens and do not consider the impact of environmental factors, for instance, the study on the influence of the salt-fog corrosion in coastal atmosphere on the seismic performance of RC-frame structures is less, and the study on the corresponding restoring force model is almost blank.

The purpose of this study is to research the seismic behavior of reinforced concrete frame joints in coastal atmosphere, and the backbone curve model of corrosion joints and the cyclic degradation index based on salt fog damage are obtained by the seismic experimental results. Then the restoring force model of joint considering the corrosion damage of steel bar is acquired and verified. The study can provide a basis for evaluating the seismic performance of the existing concrete structures in coastal atmosphere.

\section{Experimental Program}

2.1. Design and Fabrication of Specimens. Based on the design principle of "strong component, weak joint," this experiment designed and fabricated six RC frame beamcolumn joint specimens, which were taken from the beamcolumn assembly between the conventional frame antibending points. Considering the limitation of the dimensions of the environmental chamber used in this study, the geometric reduction ratio of the joint specimen was $1: 3$. The main research parameters were the axial compression ratio and the degree of steel corrosion, and the design parameters of joint specimens are shown in Table 1. The joint specimens were $2.2 \mathrm{~m}$ long, $1.45 \mathrm{~m}$ high, and the cross-section of the beam was $150 \times 250 \mathrm{~mm}^{2}$, the cross-section of the column was $200 \times 200 \mathrm{~mm}^{2}$, the concrete strength grade was C30, the longitudinal bars of the beam-column members were all HRB335, and the stirrups were all HPB235. Cross-section and reinforcement details of the six joint specimens are shown in Figure 1.

The mixing ratio for C30 concrete was $320 \mathrm{~kg} / \mathrm{m}^{3}$ of cement, $870 \mathrm{~kg} / \mathrm{m}^{3}$ of sand, $870 \mathrm{~kg} / \mathrm{m}^{3}$ of fine gravel, and $135 \mathrm{~kg} / \mathrm{m}^{3}$ of water. Ordinary Portland cement P.O $32.5 \mathrm{R}$ and medium sand were used. Three standard cubic specimens of concrete were prepared under the same conditions as the RC beam-column joint specimens. The real strengths of the concrete and the reinforcement bars were determined via material property tests. The average cubic compressive strength of the concrete was $27.03 \mathrm{MPa}$, and the properties of the reinforcement bars are shown in Table 2.

\subsection{Specimen Corrosion Program. Neutral salt spray (NSS)} tests [28] were carried out in the large-scale climate simulation laboratory at the Xi'an University of Architecture and Technology (Figure 2). To accelerate corrosion, $5 \%$ of $\mathrm{NaCl}$ was added to the specimens when pouring concrete except 0.3-No. After 28 days of natural conservation, the specimens were moved into the artificial climate laboratory for rapid salt spray corrosion. In order to make the indoor salt fog concentration constant, intermittent spray mist spray was used. In a one-hour cycle, the salt spray was stopped for 40 minutes after spraying for 20 minutes. This process was carried out for a total of 3 hours, and then the temperature in the climate chamber was raised to $60^{\circ} \mathrm{C} \pm 2^{\circ} \mathrm{C}$ for drying for 2 hours. Afterwards, the temperature was reduced to $45^{\circ} \mathrm{C}$ at a rate of $0.5^{\circ} \mathrm{C}$ per minute, and the room humidity was 
TABle 1: Design parameters of specimens.

\begin{tabular}{lcccc}
\hline Specimen no. & $n$ & Corrosion degree & Design crack width $(\mathrm{mm})$ & Designed salt fog cycle (times) \\
\hline $0.3-\mathrm{No}$ & 0.3 & None & 0 & 0 \\
0.3 -sl & 0.3 & Slight & 0.75 & 446 \\
$0.3-$ Mo & 0.3 & Moderate & 1.20 & 806 \\
$0.3-\mathrm{Se}$ & 0.3 & Severe & 1.50 & 1024 \\
$0.1-\mathrm{Mo}$ & 0.1 & Moderate & 1.20 & 806 \\
$0.45-\mathrm{Mo}$ & 0.45 & Moderate & 1.20 & 806 \\
\hline
\end{tabular}

$n$ is the axial compression ratio.

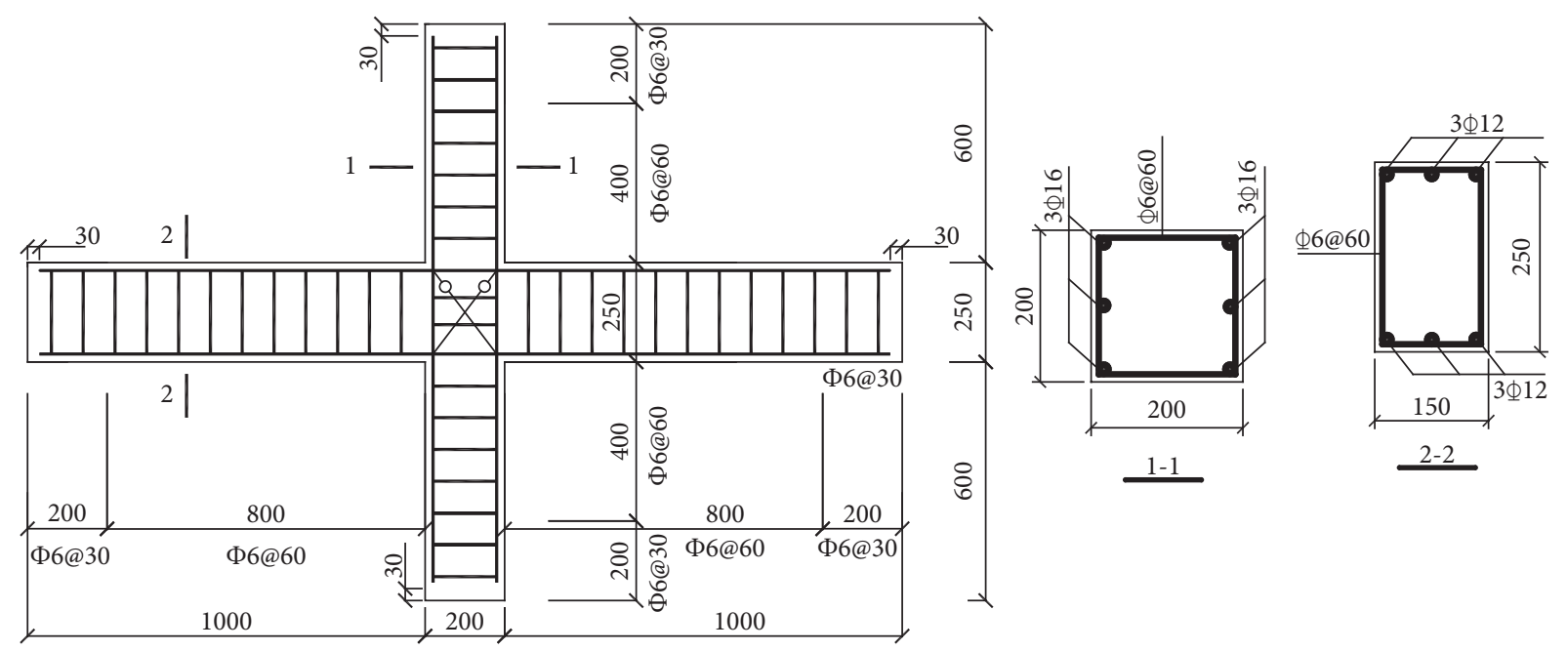

$\multimap-$ Dial indicator

FIgURE 1: Dimensions and reinforcement details of the specimens (unit: mm).

TABLE 2: Mechanical properties of the reinforcement bars.

\begin{tabular}{lccc}
\hline Diameter $(\mathrm{mm})$ & Yielding strength $f_{y}(\mathrm{MPa})$ & Ultimate strength $f_{u}(\mathrm{MPa})$ & Elastic modulus $E_{s}(\mathrm{MPa})$ \\
\hline \$6 & 305 & 420 & $2.1 \times 10^{5}$ \\
\$12 & 350 & 458 & $2.0 \times 10^{5}$ \\
\$16 & 340 & 455 & $2.0 \times 10^{5}$ \\
\hline
\end{tabular}

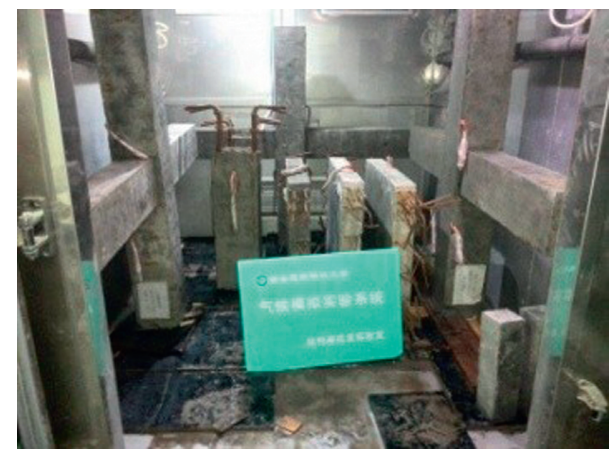

FIGURE 2: Photo of salt spray corrosion testing process.

controlled at about $90 \%$. The salt fog drying conversion time was set to 30 minutes. Therefore, a salt spray corrosion cycle takes 6 hours and 4 cycles per day. The schematic diagram of the wet-dry cycles is shown in Figure 3.

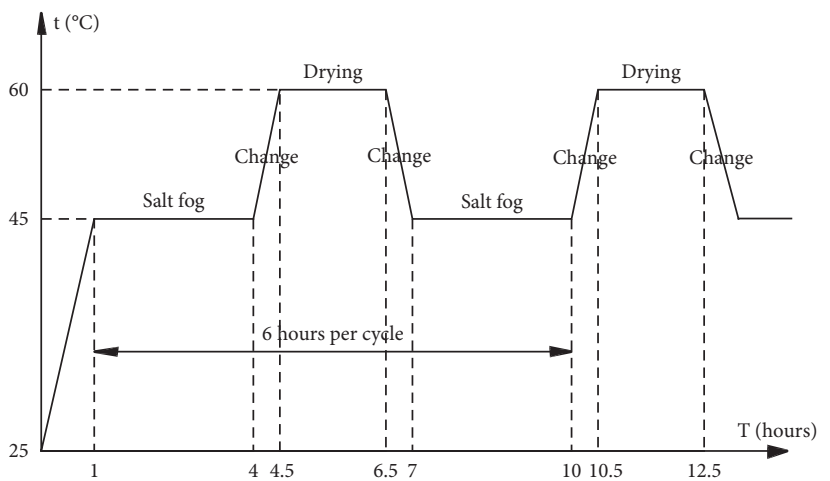

FIgURE 3: Schematic diagram of dry-wet cycles [29].

2.3. Instrumentation and Structural Test Procedures. The cyclic loading test setup and measurement configuration are shown in Figure 4 . The target vertical load was exerted on the 

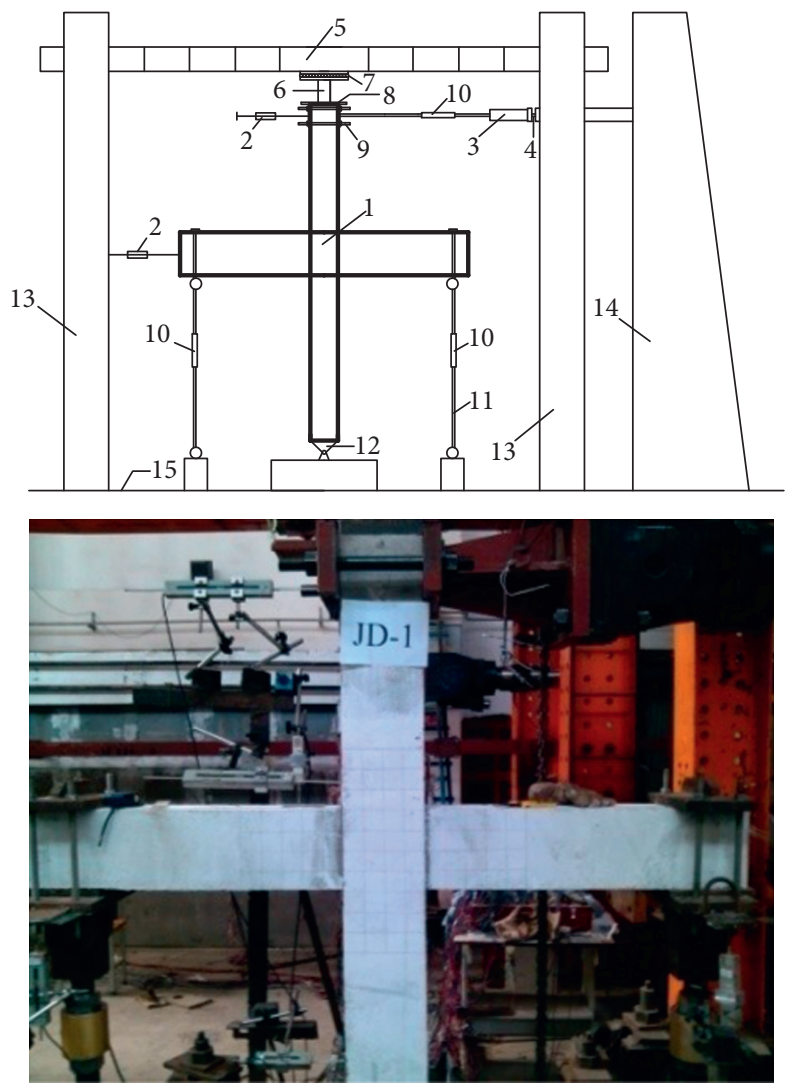

FIgURE 4: Test setup and arrangement of instruments. (1) Joint specimen. (2) LVDTs. (3) Hydraulic actuator. (4) Lateral load transfer assembly. (5) Reaction beam. (6) Hydraulic jack and pressure sensor. (7) Sliding support. (8) Pad. (9) Rolled screw. (10) Load sensor. (11) Rigid chain support. (12) Space ball hinge. (13) Gantry. (14) Reaction wall. (15) Strong floor.

specimens via hydraulic jacks and a pressure sensor was placed between the top of the column and the jack. At the same time, two load sensors were arranged at the beam ends to measure the tensile and compressive loads generated at the beam ends during the loading process. Linear variable displacement transducers (LVDTs) were installed to monitor lateral displacements. The lateral displacements at the loading point were measured by a horizontal LVDT, which had a height of $1650 \mathrm{~mm}$ to the upper surface of the strong floor. In order to prevent local compression failure of the concrete during loading, steel pads were provided at the loading point and the support position.

According to "specification of testing methods for earthquake resistant building" [30], a force-displacement hybrid control system was adopted. A load-controlled step before longitudinal reinforcement yield and a displacementcontrolled after longitudinal reinforcement yield were adopted in the lateral loading procedure, as shown in Figure 5. The MTS actuator stopped when residual lateral load decreased to $85 \%$ of the peak load.

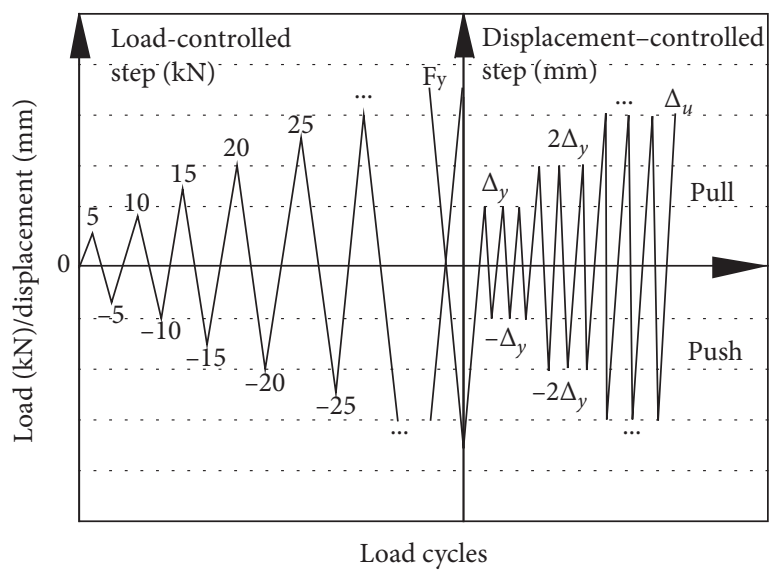

FIGURE 5: Loading protocol.

\section{Experimental Results and Discussion}

\subsection{Corrosion Phenomenon}

(1) The artificial climate corrosion process is complicated and the control method for the corrosion degree of the components is still not perfected. Jin et al. [31] pointed out that the corrosion crack width can be used to characterize the corrosion degree of the component. Therefore, a crack observer with an accuracy of $0.01 \mathrm{~mm}$ and a measuring range of 0 to $10 \mathrm{~mm}$ was used to periodically observe the rust expansion crack on the surface of the test pieces to control the crack width. To reduce the dispersion, the cracks formed in the original curing process were removed, and multiple main cracks were recorded and averaged. When the specimens' rust expansion cracks reached the expected design width, the test pieces were taken out of the artificial climate chamber in batches.

(2) The concrete of specimens with different degrees of rust were partially damaged, and then, several sections of stirrups and longitudinal reinforcements were taken out at the ends and middle portions of the test specimens, respectively. The corrosion state was observed, the cumulative mass loss rate was determined, and the material properties (take the average values) were tested. The results showed that the corrosion degrees of different specimens were not the same, and the differences in the corrosion degrees of stirrups were obvious. The corrosion degrees of longitudinal bars in beams and columns were relatively light, but the corrosion of the longitudinal reinforcements in columns were more serious than beams. The corrosion degrees of the stirrups in the core areas were significantly greater than that of the longitudinal in beams and columns.

(3) Took stirrups and beam and column longitudinal reinforcements on both sides 3 for each with a length of $30 \mathrm{~cm}$, after numbering, scraped the corrosion 
products, washed the rusted products in $12 \%$ hydrochloric acid solution, then rinsed in clean water, and neutralized in lime water, finally rinsed in water and dry, and recorded the weight of the uncorroded part. In order to reduce the discrete type of test, the cumulative mass loss rates of steel bars were averaged to the nearest $0.01 \%$ and calculated according to equation (1). The calculated values are shown in Table 3.

$$
\eta_{s}=\frac{g_{0}-g}{g_{0}} \times 100 \% .
$$

Here, $\eta_{s}$ is the cumulative mass loss rate of steel bars; $g_{0}$ and $g$ are the weight of the un-corroded and corroded steel bars, respectively.

(4) Mechanical properties of rusted steel bars were tested, and yield strength, ultimate strength, and elastic modulus were obtained, as shown in Table 4.

From Tables 3 and 4, it can be seen that the mechanical properties of steel bars with different corrosion degrees have been reduced to varying degrees. The experiment showed that under the salt spray corrosion, pitting corrosion of steel bars occurred, and the effective section areas reduced. When the reinforcements were stressed, the stress was highly concentrated in the pitted regions, which caused the early destruction of the steel bars.

3.2. Cracking and Failure Patterns of RC Frame Joint Specimens. Figure 6 shows the final failure modes of the specimens. The failure process of all joint specimens was the beam ends concrete cracked first and then yielded, after that, with the further increase of horizontal load, the core concrete was rapidly cracked, and the stirrups in the core area yielded until failed. However, with the increase of the design corrosion cracks widths (such as 0.3-No, 0.3-Sl, 0.3-Mo, 0.3-Se), the earlier the cracking and yielding of concrete at the beam ends occurred, the relatively rapid crack development of the core concrete, and the ductility of the specimens was reduced. When the specimens have the same crack widths and different axial compression ratios (such as 0.1-Mo, 0.45-Mo), the larger the axial compression ratio, the higher the bearing capacity.

3.3. Hysteretic Loops. Figure 7 shows the load-lateral displacement hysteresis of joint specimens under low cyclic loads. Observations made based on Figure 7 are summarized in the following:

(1) In the virgin loading, the specimens were in the elastic stage. There was a linear relationship between load and displacement, and the paths of loading and unloading were basically in coincidence. As the load amplitude increased, the slope of hysteresis loops decreased gradually; stiffness degradation during the reloading paths and the residual deformation at the end of unloading paths began to appear, and specimens were in the elastic-plastic stage. After reaching the peak value, the strength and stiffness degradation became more and more obvious with the increase of lateral displacement, and the hysteresis loops exhibited obvious "pinch-in" phenomenon.

(2) There were big differences in the hysteresis loops' shape between heavily rusted specimens and uncorroded. The concrete manifestation was that as the corrosion degree increase, the peak value and slope of the hysteresis loops gradually decreased, the plumpness of the hysteresis curves gradually decreased, and the pinching phenomenon became more and more obvious, which indicated that the energy consumption of the specimens was gradually reduced.

(3) For specimens 0.3-Mo, 0.1-Mo, and 0.45-Mo, it can be seen from the hysteresis curves that if the axial pressure of the joint is relatively large (e.g., 0.45-Mo), its ultimate displacement is decreased and the ductility is reduced.

3.4. Pseudo-Static Test Results. The load and displacement values of the specimens are shown in Table 5. Based on Table 5, the following observations and interpretations can be made: (1) when the axial compression ratio was the same, with the increase of the stirrup cumulative mass loss rate, the cracking, yielding, and peak loads were decreased. (2) As the cumulative mass loss rate of stirrups increased, the yield displacements of specimens 0.3-Sl, 0.3-Mo, and 0.3-Se changed little compared with that of undamaged specimen 0.3 -No, while the peak and ultimate displacements basically showed the decreasing trend. (3) When the corrosion degrees were similar, the cracking, yielding, and peak loads of specimens $0.1-\mathrm{Mo}, 0.3-\mathrm{Mo}$, and $0.45-\mathrm{Mo}$ increased gradually with the increase of axial compression ratio, but the increase was small. (4) When the corrosion degrees were similar, the variation of yielding, peak, and ultimate displacements of specimens 0.1-Mo, 0.3-Mo, and 0.45-Mo were not obvious with the increase of axial compression ratio.

The backbone curves of specimens are shown in Figure 8. As Figure 8(a) shows, the yielding, peak, and ultimate load of the corrosion specimens were all lower than the intact specimen. Before yielding, the backbone curves basically coincided and the rigidity changed little; after yielding, the straight section of the backbone curves began to shorten; and after the peak load, the descending stage gradually became steeper. With the increase of the corrosion degree, the bearing capacity and ductility of the specimens were gradually degraded. As Figure 8(b) shows, the higher the axial compression ratio is, the higher the peak value of the backbone curve is; however, the smaller the corresponding displacement, the steeper the descending branch of the backbone curve become. It indicated that for the salt spray damaged RC frame joints, the load carrying capacity increased, whereas the deformability capacity decreased and the strength decay become more abrupt with the increase of axial compression.

3.5. Hysteretic Dissipation Energy. The energy dissipation capacity of RC frame specimens was analyzed in this study by using the equivalent viscosity damping coefficient and work index $[32,33]$. 
TABLE 3: Average cumulative mass loss rate of reinforcements.

\begin{tabular}{|c|c|c|c|}
\hline \multirow{2}{*}{ Specimen no. } & \multicolumn{3}{|c|}{ Cumulative mass loss rate (\%) } \\
\hline & Core stirrups & Longitudinal bars in the beams & Longitudinal bars in the columns \\
\hline $0.3-\mathrm{No}$ & 0 & 0 & 0 \\
\hline $0.3-\mathrm{Sl}$ & 3.72 & 1.98 & 2.23 \\
\hline 0.3-Mo & 6.38 & 2.76 & 3.13 \\
\hline $0.3-\mathrm{Se}$ & 10.57 & 4.36 & 5.02 \\
\hline 0.1-Mo & 6.41 & 1.92 & 2.34 \\
\hline 0.45-Mo & 6.82 & 2.53 & 3.14 \\
\hline
\end{tabular}

TABLE 4: Mechanical properties of corroded reinforcements.

\begin{tabular}{|c|c|c|c|c|c|c|c|c|c|}
\hline \multirow{2}{*}{ Specimen no. } & \multicolumn{3}{|c|}{ Yield strength $(\mathrm{MPa})$} & \multicolumn{3}{|c|}{ Ultimate strength $(\mathrm{MPa})$} & \multicolumn{3}{|c|}{ Elastic modulus $(\mathrm{GPa})$} \\
\hline & $\phi 6$ & $\Phi 12$ & $\Phi 16$ & $\phi 6$ & $\Phi 12$ & $\Phi 16$ & $\phi 6$ & $\Phi 12$ & $\Phi 16$ \\
\hline $0.3-\mathrm{No}$ & 305.0 & 350.0 & 340.0 & 420.0 & 458.0 & 455.0 & 210 & 200 & 200 \\
\hline $0.3-\mathrm{Sl}$ & 304.4 & 349.5 & 339.6 & 418.0 & 456.5 & 453.7 & 209.2 & 199.4 & 199.4 \\
\hline 0.3-Mo & 303.9 & 349.5 & 339.4 & 416.5 & 456.5 & 453.7 & 208.7 & 199.7 & 199.3 \\
\hline $0.3-\mathrm{Se}$ & 303.2 & 349.2 & 339.1 & 414.0 & 455.5 & 452.0 & 208.4 & 199.6 & 199.3 \\
\hline $0.1-\mathrm{Mo}$ & 303.9 & 349.6 & 339.6 & 416.5 & 456.5 & 453.7 & 208.5 & 199.6 & 199.6 \\
\hline 0.45-Mo & 303.9 & 349.6 & 339.5 & 416.3 & 456.6 & 453.2 & 208.5 & 199.7 & 199.7 \\
\hline
\end{tabular}

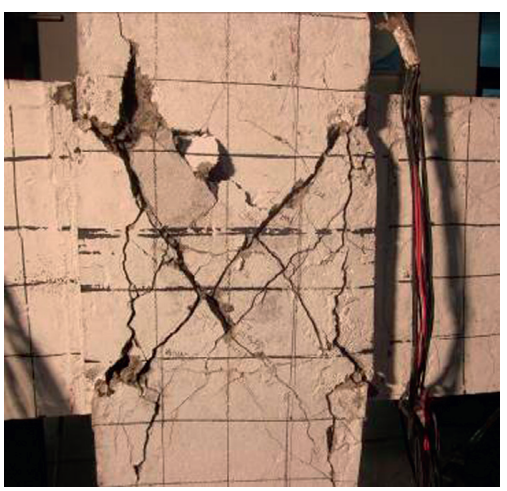

(a)

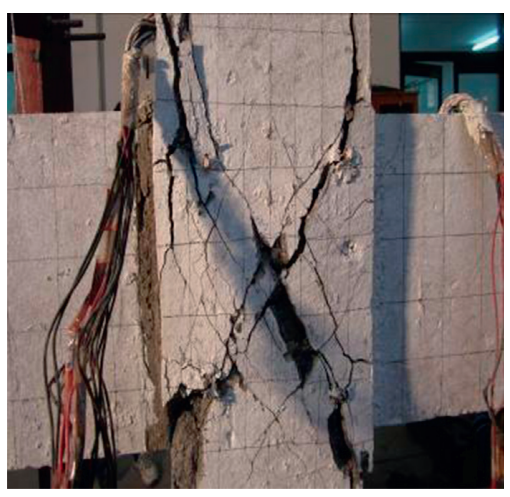

(d)

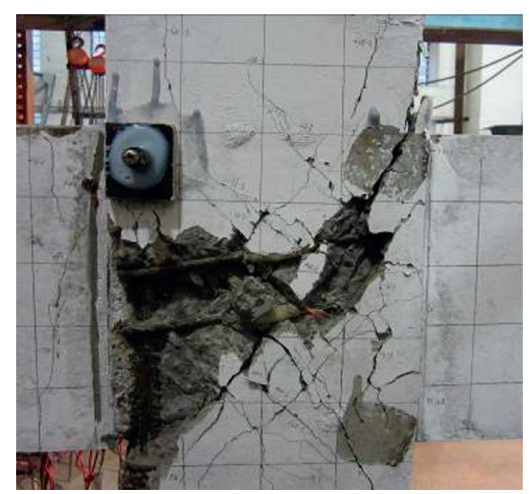

(b)

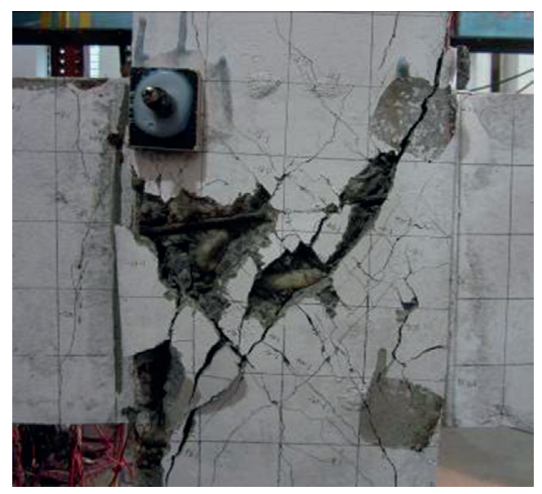

(e)

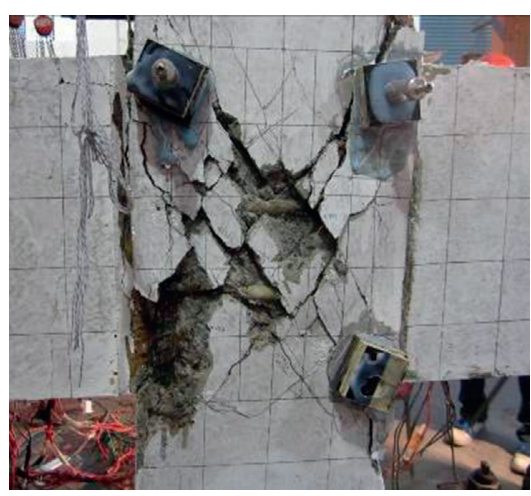

(c)

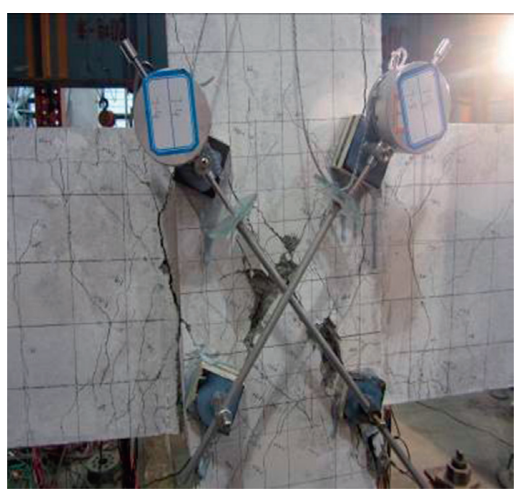

(f)

Figure 6: Failure patterns of specimens. (a) 0.3-No. (b) 0.3-Sl. (c) 0.3-Mo. (d) 0.3-Se. (e) 0.1-Mo. (f) 0.45-Mo.

3.5.1. Equivalent Viscous Damping Coefficient. The equivalent viscous damping coefficient $h_{e}$ reflects the energy dissipation capacity of the structure or component under an loading and unloading cycle, which can be calculated from.

$$
h_{e}=\frac{1}{2 \pi} \frac{S_{\mathrm{ABCD}}}{S_{\mathrm{OBE}}+S_{\mathrm{ODF}}},
$$

where $S_{\mathrm{ABCD}}$ is the area of enclosed hysteresis loop $\mathrm{ABCD}$ 


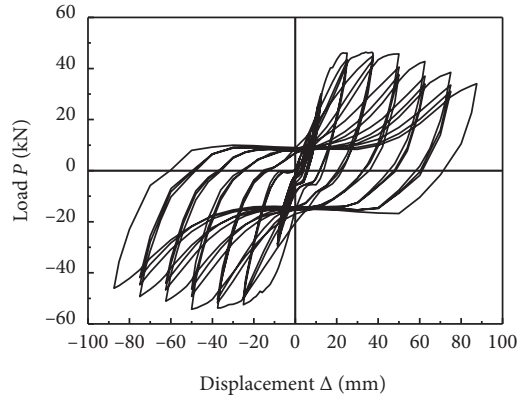

(a)

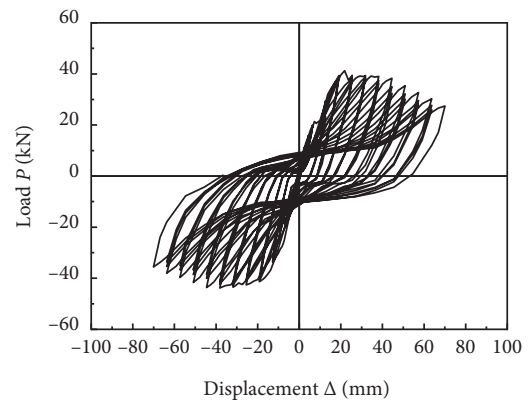

(d)

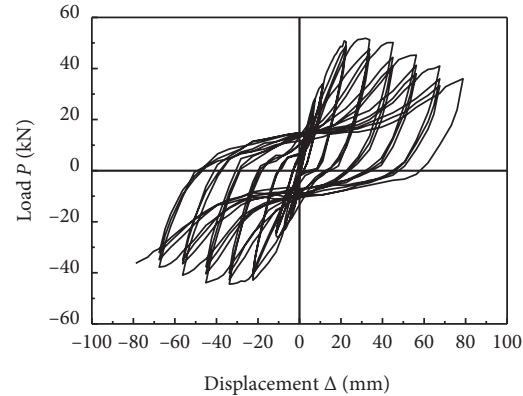

(b)

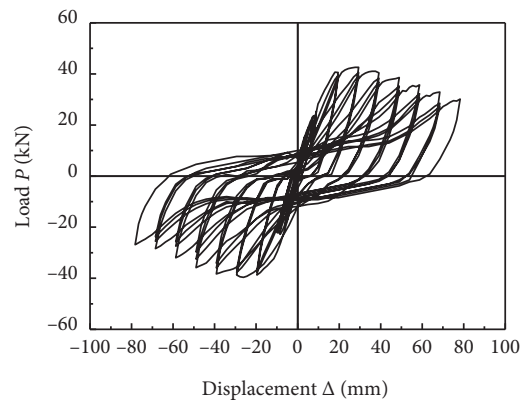

(e)

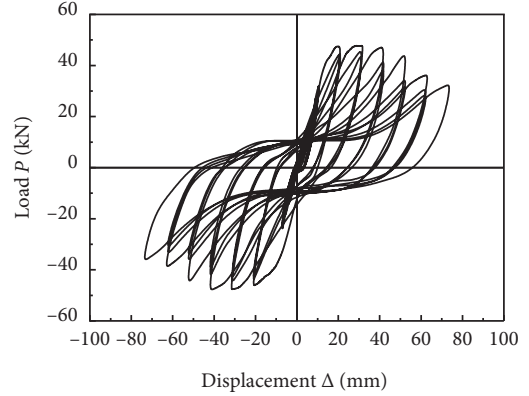

(c)

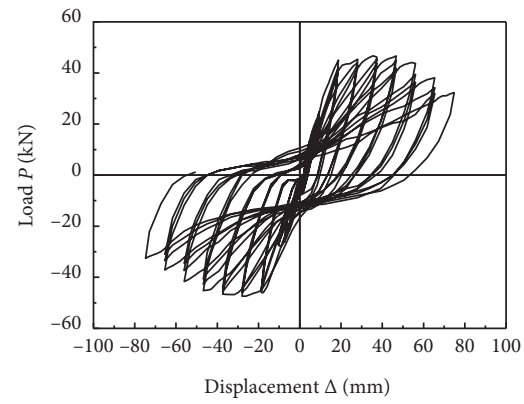

(f)

Figure 7: Hysteretic curves of specimens. (a) 0.3-No. (b) 0.3-Sl. (c) 0.3-Mo. (d) 0.3-Se. (e) 0.1-Mo. (f) 0.45-Mo.

TABLE 5: Test results of specimens.

\begin{tabular}{|c|c|c|c|c|c|c|c|c|c|}
\hline \multirow[b]{2}{*}{$\begin{array}{l}\text { Specimen } \\
\text { no. }\end{array}$} & \multirow{2}{*}{$\begin{array}{l}\text { Axial } \\
\text { compression } \\
\text { ratio }\end{array}$} & \multirow{2}{*}{$\begin{array}{c}\text { Cumulative } \\
\text { mass } \\
\text { loss rate } \eta_{s}(\%)\end{array}$} & \multirow{2}{*}{$\begin{array}{l}\text { Cracking } \\
P_{c r}(\mathrm{KN})\end{array}$} & \multicolumn{2}{|c|}{ Yielding } & \multicolumn{2}{|c|}{ Peaking } & \multirow[b]{2}{*}{$\begin{array}{l}\text { Limit displacement } \Delta_{u} \\
(\mathrm{~mm})\end{array}$} & \multirow[b]{2}{*}{$\begin{array}{l}\text { Ductility } \\
\text { factor } \mu\end{array}$} \\
\hline & & & & $\begin{array}{c}P_{y} \\
(\mathrm{KN})\end{array}$ & $\begin{array}{c}\Delta_{y} \\
(\mathrm{~mm})\end{array}$ & $\begin{array}{l}P_{\max } \\
(\mathrm{KN})\end{array}$ & $\begin{array}{l}\Delta_{\max } \\
(\mathrm{mm})\end{array}$ & & \\
\hline $0.3-\mathrm{No}$ & 0.3 & 0 & 37.2 & 42.5 & 14.5 & 54.3 & 50.3 & 87.5 & 6.03 \\
\hline $0.3-\mathrm{Sl}$ & 0.3 & 3.72 & 36.3 & 39.4 & 14.4 & 50.3 & 31.9 & 74.7 & 5.19 \\
\hline $0.3-\mathrm{Mo}$ & 0.3 & 6.38 & 32.3 & 37.5 & 14.1 & 46.8 & 40.3 & 71.2 & 5.05 \\
\hline $0.3-\mathrm{Se}$ & 0.3 & 10.57 & 28.5 & 30.7 & 14.1 & 42.7 & 38.2 & 66.1 & 4.69 \\
\hline 0.1-Mo & 0.1 & 6.41 & 30.1 & 36.3 & 13.1 & 40.6 & 39.1 & 77.6 & 5.92 \\
\hline $0.45-\mathrm{Mo}$ & 0.45 & 6.82 & 34.5 & 38.6 & 15.4 & 47.4 & 37.8 & 74.1 & 4.81 \\
\hline
\end{tabular}

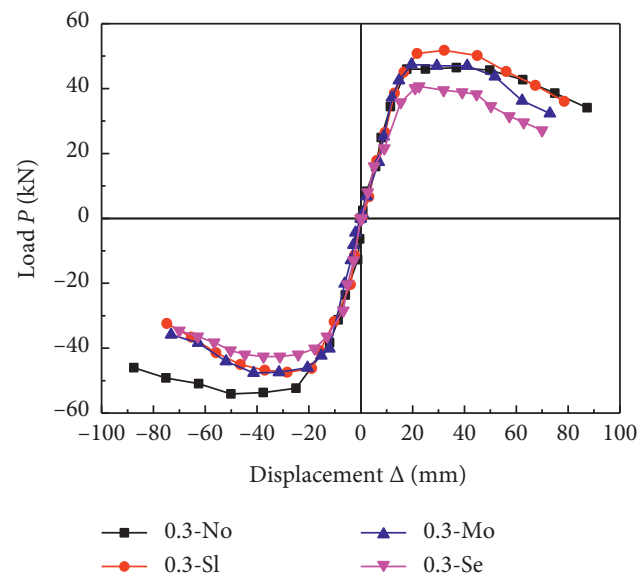

(a)

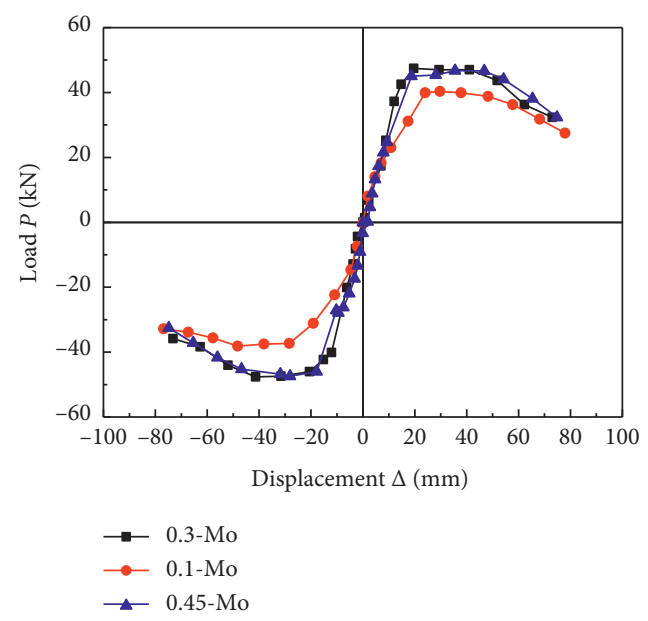

(b)

FIGURE 8: The backbone curves of specimens. (a) Corrosion-degree-induced changes in backbone curve. (b) Axial-compression-ratioinduced changes in backbone curve. 
and $S_{\mathrm{OBE}}$ and $S_{\mathrm{ODF}}$ are areas of triangles $\mathrm{OBE}$ and ODF, respectively, as shown in Figure 9.

The equivalent viscous damping coefficients $h_{\mathrm{em}}$ and $h_{\mathrm{eu}}$, which corresponds to the maximum load and the ultimate load, respectively, are listed in Table 6 . It could be seen that compared with un-corroded specimen, the equivalent viscous coefficients of the corrosion specimens in the limit state decrease with the increase of the cumulative mass loss rate, which demonstrates that the energy dissipation capacity of the corroded components are reduced in the limit state.

3.5.2. Work Index. The work index $I_{w}$ defined by Gosain [33] can be calculated as follows:

$$
I_{w}=\frac{\sum_{i=1}^{n} P_{i} \Delta_{i}}{\left(P_{y} \Delta_{y}\right)}
$$

where $P_{i}$ is the peak load in the ith cycle, $\Delta_{i}$ is the displacement corresponding to $P_{i}$, and $P_{y}$ and $\Delta_{y}$ are the yielding load and displacement, respectively. The calculation results are shown in Table 6 . It could be seen that as the cumulative mass loss rate increased, both the equivalent viscosity coefficient $h_{e}$ and the work index $I_{w}$ gradually decreased, which indicated that the energy dissipation capacity of the specimens were reduced. So corrosion could degrade the energy consumption of components.

\section{Restoring Force Model Establishment}

To study the influence of salt spray corrosion on the deformation performance of the $\mathrm{RC}$ frame joints and the entire assembly, this study first calculated the shear deformation in the joint core region based on the experimental data of the diagonal length, and then the corresponding shear force was calculated to establish the shear-shear deformation relationship curve. Meanwhile, it can be seen that the restoring force model of the corroded specimen and the uncorroded specimen were similar in shape, but as the reinforcement corrosion severely weakened the bond performance between the steel bars and the concretes, the stress between them was changed, as well as some feature points of the backbone curves. So after analyzing the experimental data and taking into account the restoring force model of the three-fold line shear deformation, the backbone curve model of the corrode RC frame joint was established, as shown in Figure 10. The backbone curve needs to determine five characteristic points, namely, the cracking shear $V_{\text {jcr }}$, the peak shear $V_{j \max }$, the elastic shear stiffness $K_{1}$, the hardening shear stiffness $K_{2}$, and the softening shear stiffness $K_{3}$, respectively.

\subsection{The Feature Points of Uncorroded Components}

4.1.1. The Cracking Shear $V_{\text {jcr. }}$ The cracking shear can be calculated as follows [34]:

$$
V_{\mathrm{jcr}}=\frac{\eta \varphi_{c} b_{j} h_{j} f_{t} \sqrt{1+\left(\sigma_{c} / f_{t}\right)}+\varepsilon f_{\mathrm{yv}} A_{\mathrm{svj}}\left(h_{b 0}-a_{s}^{\prime}\right)}{s},
$$

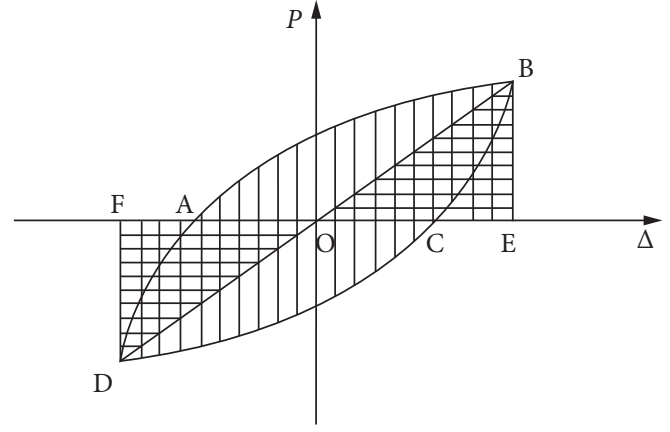

FIgURE 9: Schematic diagram for calculating equivalent viscous damping coefficient.

TABLE 6: Energy dissipation indices of specimens.

\begin{tabular}{lccc}
\hline Specimen no. & $h_{\mathrm{em}}$ & $h_{\mathrm{eu}}$ & $I_{w}$ \\
\hline 0.3-No & 0.117 & 0.240 & 55.31 \\
0.3-sl & 0.102 & 0.231 & 43.91 \\
0.3-Mo & 0.098 & 0.226 & 40.48 \\
0.3-Se & 0.096 & 0.217 & 38.49 \\
0.1-Mo & 0.097 & 0.234 & 41.53 \\
0.45-Mo & 0.112 & 0.208 & 39.85 \\
\hline
\end{tabular}

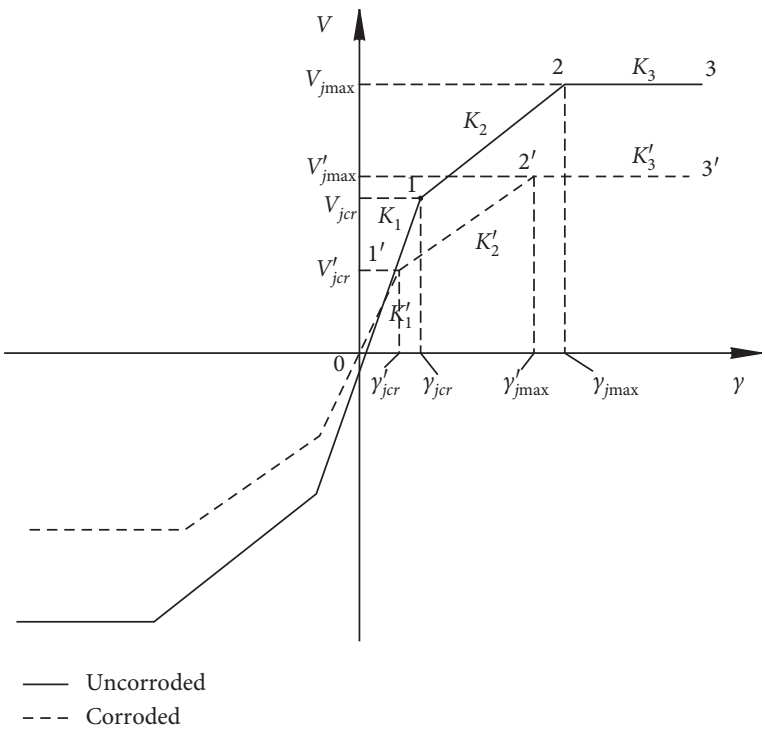

FIGURE 10: Backbone curves of restoring force model of specimens with and without being corroded.

where $\eta$ is the comprehensive coefficient of influence that takes the value 0.67 and $\varphi_{c}$ is the constraint coefficient of the beam to the joint. For the joints without the orthogonal beams, $\varphi_{c}=1.0 ; b_{j}$ and $h_{j}$ are the effective width and height of the joint core section, respectively. $\varepsilon$ is the stirrup stress development coefficient, which takes the value $0.1 ; f_{\mathrm{yv}}$ is the yield strength of stirrups in the joint; $A_{\text {svj }}$ is the sectional area of all stirrups in the same section; $s$ is the spacing of stirrups; $h_{b 0}$ is the effective height of the beam section; $a_{s}^{\prime}$ is the distance from the resultant center of the tensile reinforcement of the beam to the edge of the nearest section; and when $\sigma_{c} \geq 0.5 f_{c}, \sigma_{c}=0.5 f_{c}$. 
4.1.2. The Peak Shear $V_{j \max }$. It was often considered that the joint reached the split state as its failure criterion, the shear strength of the joint was known as the peak value at this time. After the concrete in the joint core areas were cracked, the shear force was assumed by the horizontal stirrups in the core areas and the longitudinal reinforcements on the front and back sides of the column, thereby which form a "truss mechanism." Reference on the current specification [34], the peak shear of the joint could be determined as follows:

$$
V_{j \max }=1.1 \eta_{j} f_{t} b_{j} h_{j}+0.05 \eta_{j} N \frac{b_{j}}{b_{c}}+f_{\mathrm{yv}} A_{\mathrm{svj}} \frac{h_{b 0}-a_{s}^{\prime}}{s},
$$

where $\eta_{j}$ is the constraint coefficient of the orthogonal beam to the joint, $N$ is the design value of the axial force at the bottom of the column at the joint considering the design value of seismic shear force. The above value can refer to the specification [34]. At the same time, the peak shear force $V_{j \max }$ must satisfy the condition:

$$
V_{j \max }<0.3 \eta f_{c} b_{j} h_{j} .
$$

\subsubsection{Calculation of Shear Stiffness of Joints under Different Stress Stages}

(1) Elastic Shear Stiffness $K_{1}$ at Segment 01

$$
K_{1}=\mathrm{GA} \text {, }
$$

where $G$ is the elastic shear modulus and is calculated by: $G=E_{c} / 2(1+\mu), E_{c}$ is the elastic modulus of the joint concrete. $\mathrm{A}$ is the shear area of the joint core area, $\mu$ is Poisson ratio (for concrete materials, $\mu$ is $0.2)$.

(2) Hardened Shear Rigidity $K_{2}$ of Segment 12

At this stage, the joints are in an elastic-plastic state and their stiffness are degraded. The expression of $K_{2}$ is as follows:

$$
K_{2}=\alpha K_{1},
$$

where $\alpha$ is the stiffness degradation coefficient of the joint, the axial compression ratio, and the shear pressure ratio of the joint have an effect on the hardening stiffness. Based on references [35-37], the expression of $\alpha$ is as follows:

$$
\alpha=\frac{1}{4[1+10(\lambda-0.2) \sqrt{n}]},
$$

where $\lambda$ is the shear ratio of the joint $\lambda=V / f_{c} b_{j} h_{j}, n$ is the axial compression ratio of the column, $n=N / f_{c} b_{c} h_{c}$.

(3) Softening Shear Rigidity $K_{3}$ of Segment 23

According to Bazant [38], the ultimate shear capacity of a joint was about 1.2 times for its cracking capacity. Considering the importance of the joint, it is conservatively assumed that the joint would enter the ideal elastic-plastic state after it reached the cleft.
In the actual projects, the designs are based on the principle of "strong joint," and it is impossible for the joint to reach the limit state before the structure collapsed. Hence,

$$
K_{3}=0 .
$$

From the stiffness calculation formulas above, the shear deformation $\gamma_{j \mathrm{jr}}$ and $\gamma_{j \max }$ corresponding to the crack state and the peak state could be calculated.

\subsection{Calculation of Characteristic Points of Corroded} Specimens. According to the deformations of the joint core areas measured in the tests, the horizontal shear force and shear deformation in the core areas of specimens were calculated. The fitting analysis is performed to obtain the degradation of characteristic parameters of the restoring force model of corroded specimens with the variation of the stirrup corrosion ratios and the axial compression ratios. The formulas calculated the characteristic parameters considering the effects of rust damage are shown in Table 7. At the same time, fitting plots of equations (11)-(14) are shown in Figure 11.

Note: In Table $7, V_{\mathrm{jcr}}^{\prime}$ and $V_{j \max }^{\prime}$ are the cracking shear and peak shear of the rusted specimens, respectively; $\gamma_{\mathrm{jcr}}^{\prime}$ and $\gamma_{j \max }^{\prime}$ are the cracking shear deformation and the peak shear deformation of the rusted components, respectively; $K_{1}^{\prime}, K_{2}^{\prime}$, and $K_{3}^{\prime}$ are the elastic stiffness, hardening stiffness, and ultimate stiffness of the rusted component, respectively; $\eta_{s}$ is the average cumulative mass loss rate of stirrups in the joint area; $n$ is axial compression ratio.

From the correlation coefficient $R^{2}$ in Table 7 and the fitting plots in Figure 11, it could be seen that the fitted values are similar to the actual values. Using the fitting formulas and the feature point values of the good components, the characteristic point values of the specimens with different degrees of corrosion can be obtained. The results are shown in Table 8.

4.3. Establishment of Hysteresis Rules. From the hysteretic curves of specimens, we can conclude that the strength and stiffness of specimens were deteriorated during each cyclic loading with the increase of corrosion degrees. Ibarra et al. [39] researched hysteretic models that incorporated strength and stiffness deterioration, and in this research, three of the basic hysteretic models used in seismic demand evaluation were modified to include deterioration properties: bilinear, peak-oriented, and pinching. In this, the peak-oriented model incorporate an energy-based deterioration parameter [40] that controls four cyclic deterioration modes: basic strength, post-capping strength, unloading stiffness, and reloading stiffness deterioration. Four cyclic deterioration modes had been defined by the equations and interpreted with the figures in details. Therefore, referring to Ibarra et al. [39], this study chooses the peak-oriented model as the hysteretic rules of corrosion specimens, the strength and stiffness deterioration modes are shown in Figure 12, and the 
TABLE 7: Corrosion member feature point formulas.

\begin{tabular}{|c|c|c|c|}
\hline Feature points & Fitting expressions & & $R^{2}$ \\
\hline$V_{j c r}^{\prime}$ & $V_{j c r}^{\prime}=\left(-0.00488 \eta_{s} n-0.02692 \eta_{s}+0.96531\right) \cdot V_{j c r}$ & $(11)$ & 0.913 \\
\hline$\gamma_{\mathrm{jcr}}^{\prime c r}$ & $\gamma_{\mathrm{jcr}}^{\prime}=\left(0.03304 \eta_{s} n-0.02553 \eta_{s}-0.09769 n+0.3285 n^{2}+0.97157\right) \cdot \gamma_{\mathrm{jcr}}$ & $(12)$ & 0.878 \\
\hline$V_{j \max }^{\prime}$ & $V_{j \max }^{\prime}=\left(-0.07278 \eta_{s} n+0.88385 n+0.72829\right) \cdot V_{j \max }$ & $(13)$ & 0.915 \\
\hline$\gamma_{j \max }^{\prime \prime N a n}$ & $\gamma_{j \max }^{\prime}=\left(0.75567 \eta_{s}+16.895 n-2.5878 \eta_{s} n-4.0546\right) \cdot \gamma_{j \max }$ & $(14)$ & 0.990 \\
\hline$K_{1}^{\prime}$ & $K_{1}^{\prime}=V_{\mathrm{jcr}}^{\prime} / \gamma_{\mathrm{jcr}}^{\prime}$ & $(15)$ & - \\
\hline$K_{2}^{\prime}$ & $K_{2}^{\prime}=\left(V_{j \max }^{\prime}-V_{j \mathrm{cr}}^{\prime \prime}\right) /\left(\gamma_{j \max }^{\prime}-\gamma_{\mathrm{jcr}}^{\prime}\right)$ & $(16)$ & - \\
\hline$K_{3}^{\prime}$ & $K_{3}^{\prime}=K_{3}=0$ & $(17)$ & - \\
\hline
\end{tabular}

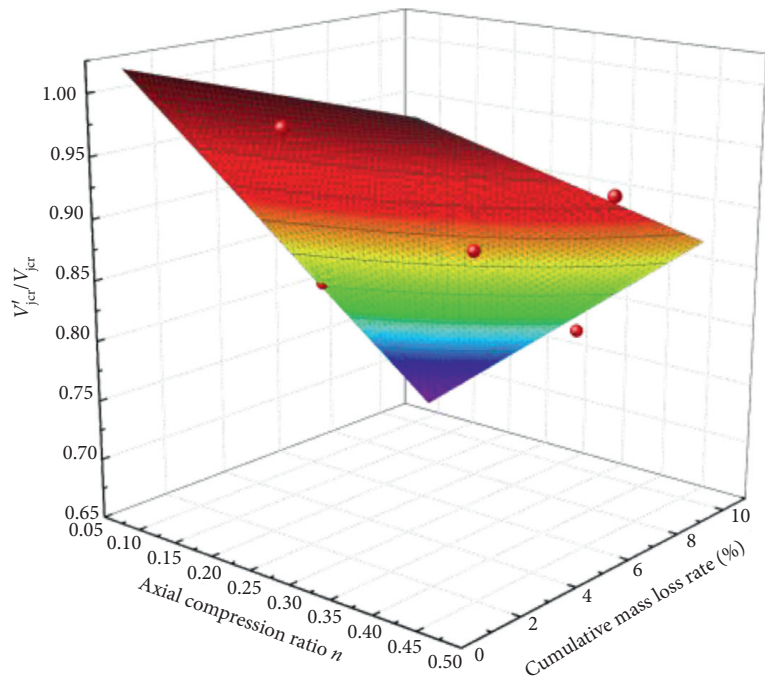

(a)

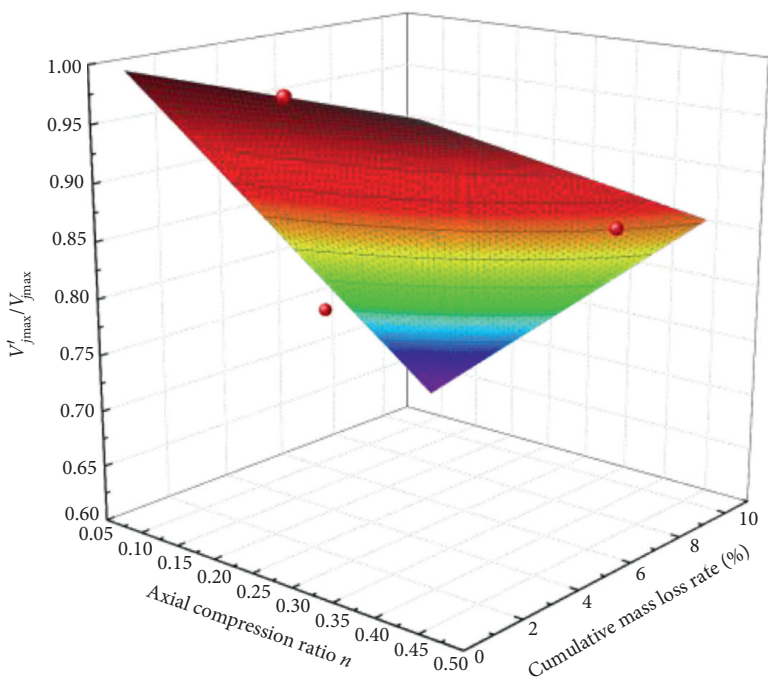

(c)

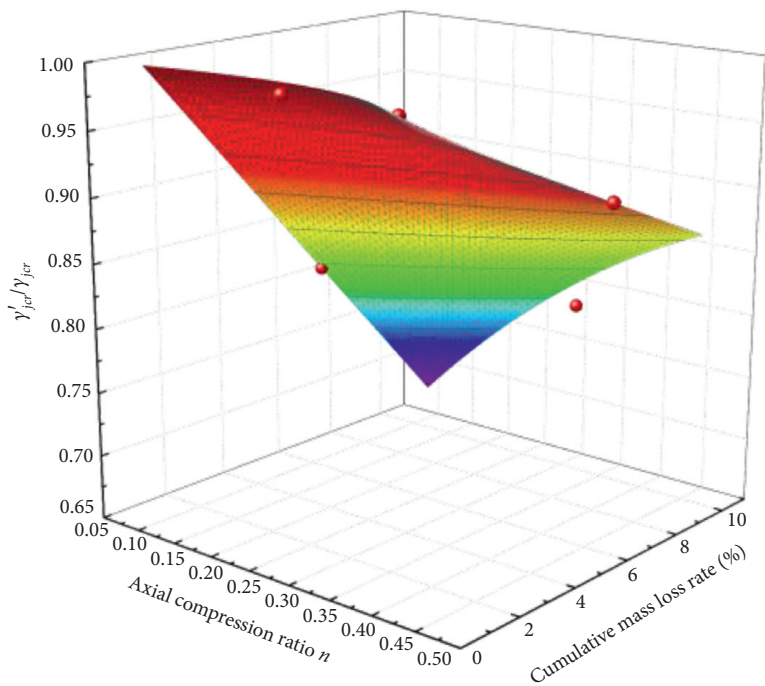

(b)

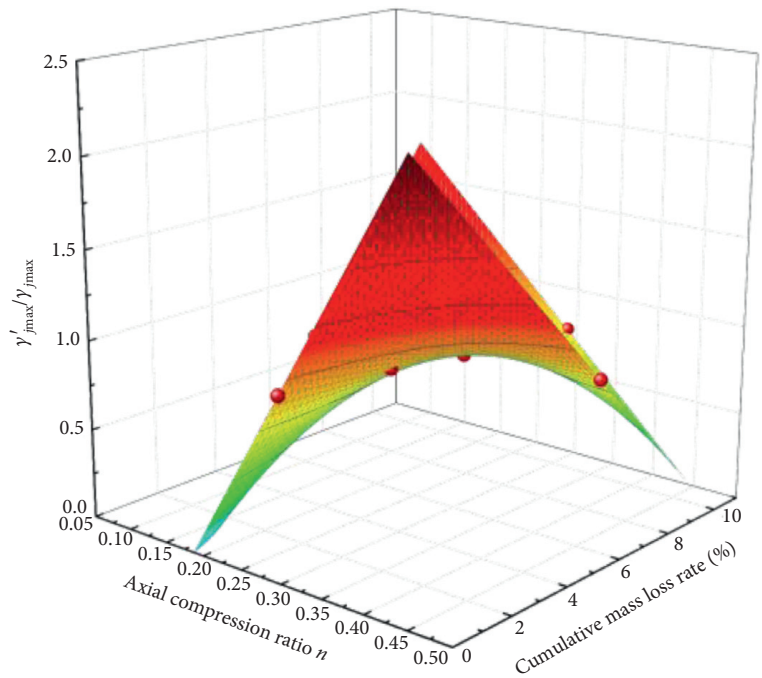

(d)

FIGURE 11: Fitting plots of the characteristic points formulas: (a) Fitting plot of equation (11). (b) Fitting plot of equation (12). (c) Fitting plot of equation (13). (d) Fitting plot of equation (14).

equations of individual cyclic deterioration modes are listed as shown in Table 9.

Note: In Table 9, $\beta_{i}$ is cyclic deterioration parameter [40]; $V_{\text {jcri }}^{ \pm}$and $V_{\text {jcr }(i-1)}^{ \pm}$are the cracking shear force after and before excursion $i$, respectively; $K_{2 i}^{ \pm}$and $K_{2(i-1)}^{ \pm}$are the hardening stiffness after and before excursion $i$, respectively; $V_{j \max i}^{ \pm}$and $V_{j \max (i-1)}^{ \pm}$are the peak shear after and before excursion $i$, respectively; $K_{\mathrm{ui}}$ and $K_{u(i-1)}$ are the unloading stiffness after and before excursion $i$, respectively; " \pm " "represents the loading direction; "+" represents the positive loading; and "-" represents the negative loading. 


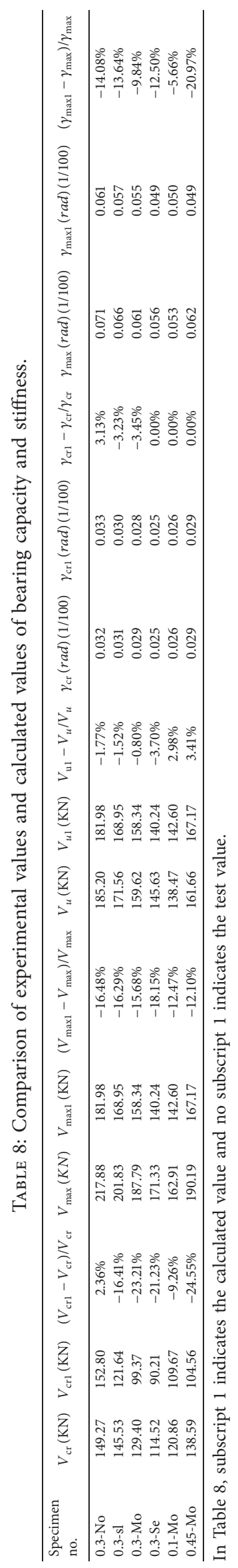




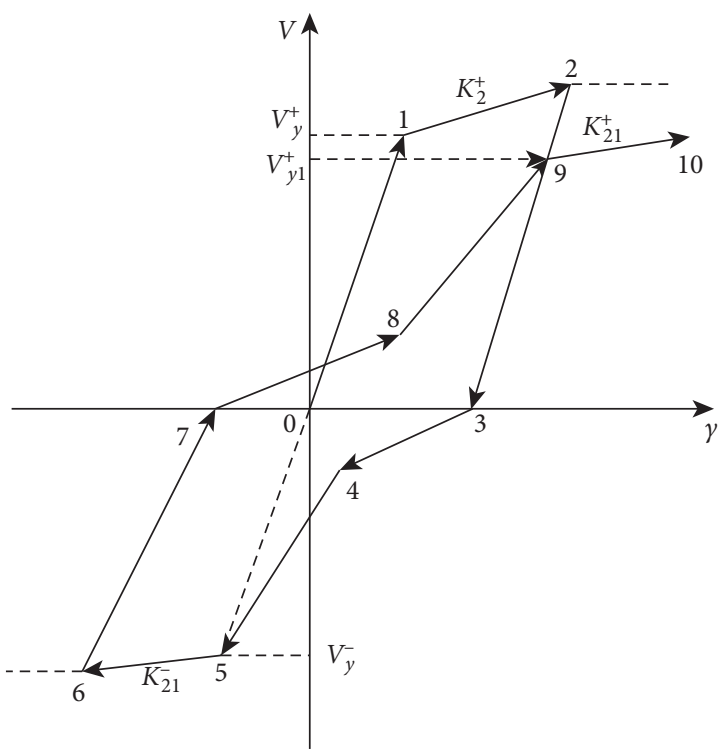

(a)

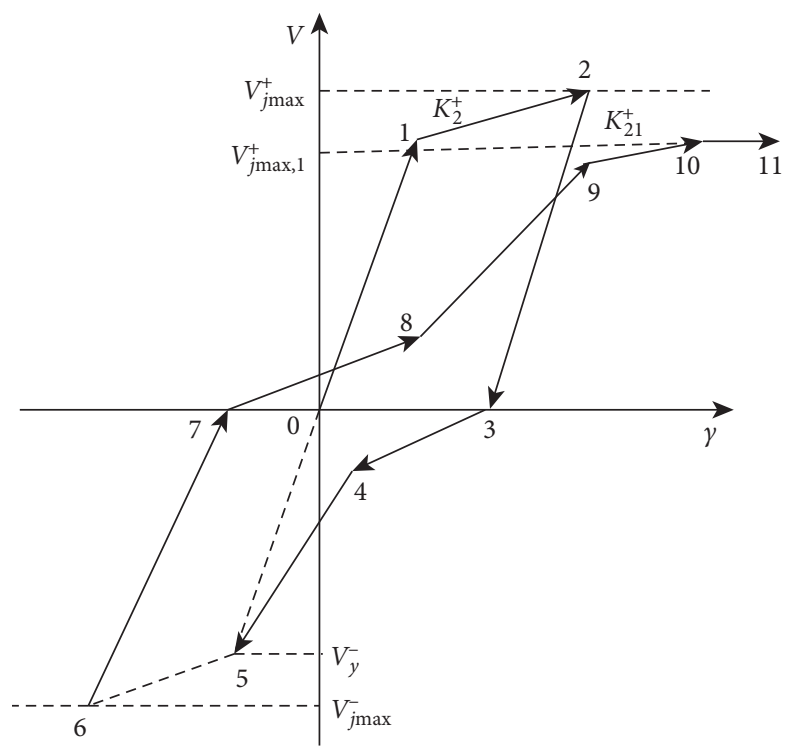

(b)

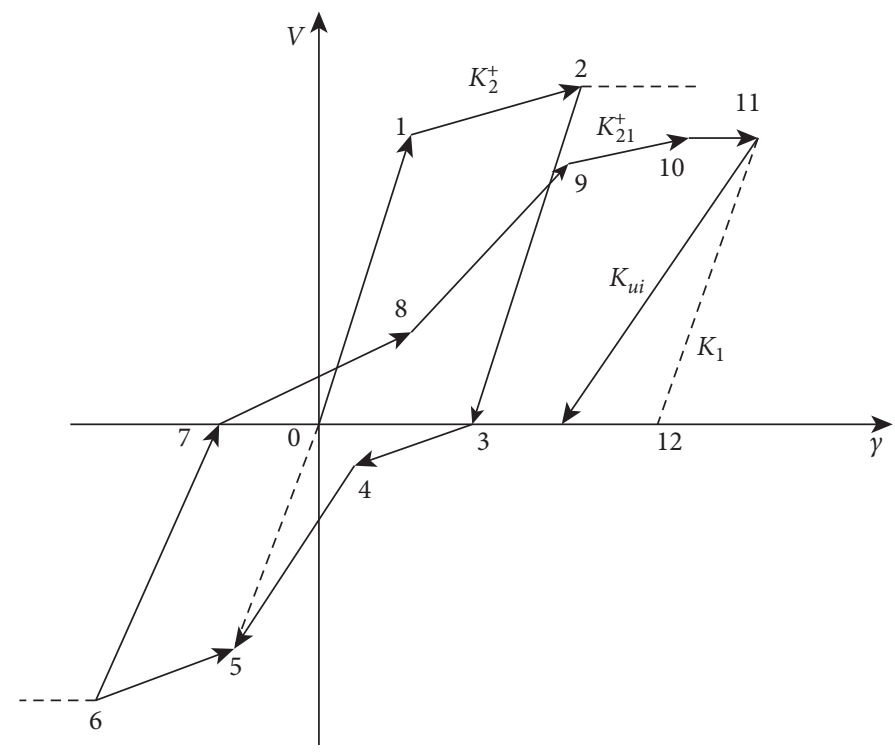

(c)

FIGURE 12: Individual deterioration modes, illustrated on a peak-oriented model: (a) basic strength deterioration. (b) Post-capping strength deterioration. (c) Unloading stiffness deterioration.

TABle 9: The equations of individual cyclic deterioration laws.

\begin{tabular}{lcc}
\hline Hysteretic rules & \multicolumn{1}{c}{ Equations of deterioration modes } \\
\hline The cracking shear degradation law & $V_{\text {jcri }}^{ \pm}=\left(1-\beta_{i}\right) V_{j \mathrm{jr}(i-1)}^{ \pm}$ & $(18)$ \\
The hardening stiffness degradation law & $K_{2 i}^{ \pm}=\left(1-\beta_{i}\right) K_{2}^{ \pm}(i-1)$ & $(19)$ \\
The peak shear degradation law & $V_{j \max i}^{ \pm}=\left(1-\beta_{i}\right) V_{j \max (i-1)}^{ \pm}$ & $(20)$ \\
The unloading stiffness degradation law & $K_{u i}=\left(1-\beta_{i}\right) K_{u(i-1)}$ & $(21)$ \\
\hline
\end{tabular}

\section{Restoration Force Model Verification}

To verify the practicability of the restoration force model proposed in this study, taking the specimens 0.3 -Se and 0.1Mo as examples, the calculated hysteresis curve is compared with the test. The comparison results are shown in Figure 13.
As seen from Figure 13, the model curve and the test curve are close to each other in the positive direction, but in the negative direction, there is a large deviation. The probable cause is that corrosion of reinforced concrete specimens is a very complicated process, and the steel reinforcements are likely to be unevenly rusted, but when 


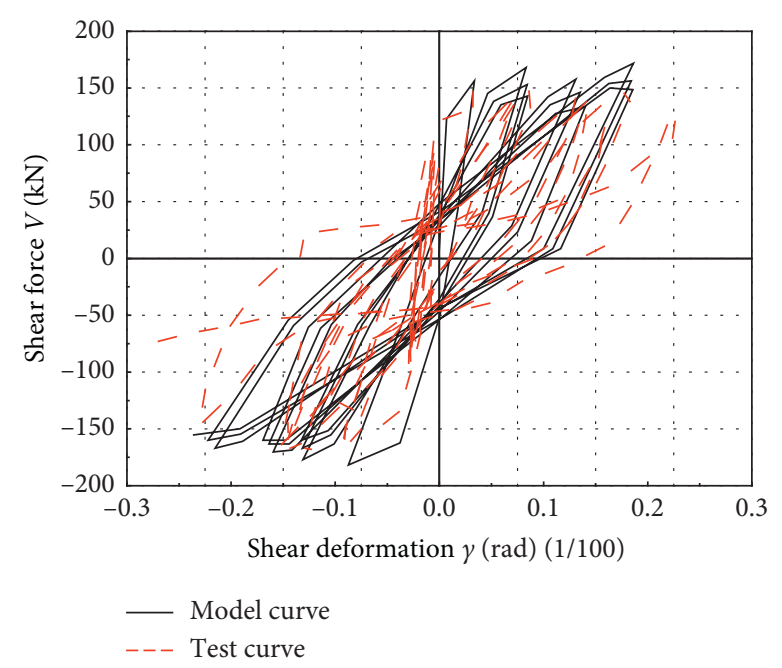

(a)

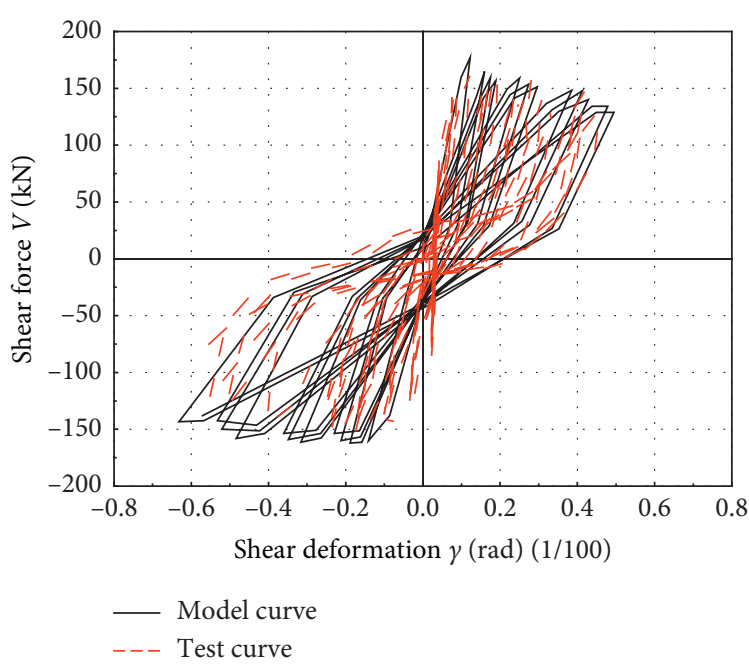

(b)

Figure 13: Comparison of calculated and test result. (a) 0.3-Se. (b) 0.1-Mo.

establishing the theoretical model, it is assumed that the specimens are uniformly rusted, so there is a difference between the experimental model and the theoretical model. 0.3 -Se and 0.1-Mo represent the severe and moderate corrosion of the specimens, respectively. The calculated results are close to the test results. The pinching effect is caused by the crack development, the bond-slip of the longitudinal beams in the loading process reaches to a certain degree. This shows that the restoring force model established has a good applicability, which can reflect the degradation of the performance of corroded components during loading truly.

\section{Conclusions}

Six RC frame beam-column joint specimens were subjected to rapid artificial climate corrosion test in the coastal environment, and then they were tested under lateral cyclic loads. The effects of cumulative mass loss rates and axial compression ratios on strength, ductility and energy dissipation capacity of beam-column joints were analyzed, and the restoring force model of corroded RC frame beamcolumn joints was studied. The following conclusions can be drawn from the test results:

(1) For the RC frame beam-column joints, the corrosion of the stirrups was more severe than the longitudinal reinforcements. Corroded stirrup weakened the restraint effect of the concrete in the core area of the joints, and the destruction of the joint area was aggravated.

(2) With the increase of cumulative mass loss rate of steel bars, the strength, ductility, and energy dissipation capacity of RC frame joint components were all degraded to varying degrees, manifested as the reduction of bearing capacity and deformation capacity of the components. When the corrosion degree was the same, the stiffness of the joint specimens decreased more significantly with the increase of the axial compression ratio. The stiffness of specimens with a relatively small axial pressure was significantly degraded before cracking and tended to be stable after yielding.

(3) The restoration force model of RC frame beamcolumn joints based on the tri-line restoring force model and considering the salt spray corrosion in coastal atmosphere accurately described the cyclic degradation and pinch effect caused by cyclic loading and corrosion damage.

(4) The calculated results of the restoring force model of corroded RC frame beam-column joints are in good agreement with the experimental results. It shows that the restoring force model would better reflect the hysteresis characteristics of the RC frame beamcolumn joints in coastal environment than un-corroded the RC frame beam-column joints, which can provide a theoretical reference for the elastic-plastic seismic response analysis of RC frame structures in the coastal environment.

\section{Data Availability}

All data used to support the findings of this study are available from the corresponding author upon request.

\section{Conflicts of Interest}

The authors declare no conflicts of interest.

\section{Acknowledgments}

The authors are grateful for the financial support received from the National Natural Science Foundation of China (no. 51678475), National Key R\&D Project (no. SQ2019YFC15011102), Industrialization Project of Shaanxi Education Department (no. 18JC020), and Xi'an Science and Technology Plan Project 
(no. 2019113813CXSF016SF026). The authors would like to thank the reviewers' efforts in reading the manuscript.

\section{References}

[1] Y. G. Du, L. A. Clark, and A. H. C. Chan, "Effect of corrosion on ductility of reinforcing bars," Magazine of Concrete Research, vol. 57, no. 7, pp. 407-419, 2005.

[2] L. Yu, R. François, V. H. Dang, V. L’Hostis, and R. Gagné, "Structural performance of RC beams damaged by natural corrosion under sustained loading in a chloride environment," Engineering Structures, vol. 96, pp. 30-40, 2015.

[3] L. Amleh and S. Mirza, "Corrosion influence on bond between steel and concrete," ACI Structural Journal, vol. 96, no. 3, pp. 415-423, 1999.

[4] Q. X. Shi, D. T. Niu, and G. Y. Yan, "Experimental research on hysteretic characteristics corroded RC members with flexural and compressive axial loads under repeated horizontal loading," Earthquake Engineering and Engineering Vibration, vol. 20, pp. 45-50, 2000.

[5] P. S. Mangat and M. S. Elgarf, "Flexural strength of concrete beams with corroding reinforcement," Structural Journal, vol. 96, pp. 149-158, 1999.

[6] P. K. Metha, "Durability of concrete-fifty years of progress?" in Proceedings of the Durability of concrete-G.M. Idorn International Symposium, American Concrete International, Detroit, MI, USA, 1991.

[7] Y.-C. Ou and N. D. Nguyen, "Influences of location of reinforcement corrosion on seismic performance of corroded reinforced concrete beams," Engineering Structures, vol. 126, pp. 210-223, 2016.

[8] Y. C. Ou and H. H. Chen, "Cyclic behavior of reinforced concrete beams with corroded transverse steel reinforcement," Journal of Structural Engineering, ASCE, vol. 140, pp. 758-782, 2014.

[9] S. S. Zheng, W. Yang, Y. T. Zhao, Q. Qin, and Y. Y. Guan, "Experimental research on the seismic behaviors of corroded RC frame beams failed in flexure-shear mode under the artificial climate," China Civil Engineering Journal, vol. 48, pp. 27-35, 2015.

[10] Y.-C. Ou, L.-L. Tsai, and H.-H. Chen, "Cyclic performance of large-scale corroded reinforced concrete beams," Earthquake Engineering \& Structural Dynamics, vol. 41, no. 4, pp. 593604, 2012.

[11] S. S. Zheng, L. G. Dong, H. S. Zuo, Q. Qin, W. Liu, and Q. Q. Li, "Experimental investigation on seismic behaviors of corroded RC frame columns in artificial climate," Journal of Building Structures, vol. 39, no. 3, pp. 28-36, 2008.

[12] J. B. Li and J. X. Gong, "Influence of rebar corrosion on seismic behavior of circular RC columns," China Journal of Highway and Transport, vol. 21, no. 4, pp. 55-60, 2008.

[13] Y. Ma, Y. Che, and J. Gong, "Behavior of corrosion damaged circular reinforced concrete columns under cyclic loading," Construction and Building Materials, vol. 29, pp. 548-556, 2012.

[14] A. Guo, H. Li, X. Ba, X. Guan, and H. Li, "Experimental investigation on the cyclic performance of reinforced concrete piers with chloride-induced corrosion in marine environment," Engineering Structures, vol. 105, pp. 1-11, 2015.

[15] D. Gan, Z. Zhou, X. H. Zhou, and K. H. Tan, "Seismic behavior tests of square reinforced concrete-filled steel tube columns connected to RC beam joints," Journal of Structural Engineering, ASCE, vol. 145, no. 3, Article ID 04018267, 2019.
[16] X. Zhou, Z. Zhou, and D. Gan, "Cyclic testing of square tubedreinforced-concrete column to RC beam joints," Engineering Structures, vol. 176, pp. 439-454, 2018.

[17] A. Kanchanadevi and K. Ramanjaneyulu, "Effect of corrosion damage on seismic behaviour of existing reinforced concrete beam-column sub-assemblages," Engineering Structures, vol. 174, pp. 601-617, 2018.

[18] J. Yang, T. Guo, S. Chai, and A. Li, "Cyclic tests on beamcolumn joints of SCOPE system with different key slot lengths and corrosion levels," Engineering Structures, vol. 201, p. 109406, 2019.

[19] S.-Y. Yang, X.-B. Song, H.-X. Jia, X. Chen, and X.-L. Liu, "Experimental research on hysteretic behaviors of corroded reinforced concrete columns with different maximum amounts of corrosion of rebar," Construction and Building Materials, vol. 121, pp. 319-327, 2016.

[20] A. Meda, S. Mostosi, Z. Rinaldi, and P. Riva, "Experimental evaluation of the corrosion influence on the cyclic behaviour of RC columns," Engineering Structures, vol. 76, pp. 112-123, 2014.

[21] Y. Yuan, X. Zhang, and Y. Ji, "A comparative study on structural behavior of deteriorated reinforced concrete beam under two different environments," China Civil Engineering Journal, vol. 39, pp. 42-46, 2006.

[22] W. P. Zhang, X. G. Wang, X. L. Gu, and D. F. Shang, "Comparative study on structural performance of reinforced concrete beams subjected to natural corrosion and accelerated corrosion," Journal of Southeast University, vol. 36, pp. 139$144,2006$.

[23] R. W. Clough and S. B. Johnston, "Effects of stiffness degradation on earthquake ductility requirements," in Proceedings of Second Japan Earthquake Engineering Symposium, pp. 227-232, Tokyo, Japan, October 1966.

[24] W. Ramberg, Description of Steel Strain Curve by Three Parameters, National Advisory Committee for Aeronautics, Washington, DC, USA, 1943.

[25] C. W. Yan, Y. Yang, J. Q. Jia, J. Zhang, and S. G. Liu, "Study on restoring force model of steel reinforced ultra high strength concrete frame joints," Engineering Mechanics, vol. 32, pp. 154-160, 2015.

[26] R. Bouc, "Forced vibration of mechanical systems with hysteresis," in Proceedings of the 4th International Conference on Nonlinear Oscillations, pp. 367-377, Prague, Czechoslovakia, October 1967.

[27] Y. X. Wen, "Method for random vibration of hysteretic systems," Journal of the Engineering Mechanics Division, vol. 102, pp. 249-263, 1976.

[28] Chinese national Standard, Standard For Corrosion Tests in Artificial Atmospheres-Salt Spray Tests (GB/T10125), China Architecture Industry Press, Beijing, China, 2012.

[29] S. S. Zheng, L. F. Sun, X. R. Liu, and W. Yang, "Experimental research on seismic behaviors of beam-column joints of corroded RC frame in the coastal atmosphere," China Civil Engineering Journal, vol. 48, no. 12, pp. 63-71, 2015.

[30] Chinese national Standard, Standard For Specification Of Testing Methods for Earthquake Resistant Building (JGJ10196), China Architecture Industry Press, Beijing, China, 1997.

[31] W. L. Jin, Y. S. Yuan, and J. Wei, Design Theory and Method of Concrete Durability under Chloride Ion Corrosion, Science Press, Beijing, China, 2011.

[32] Q. F. Yao, Civil Engineering Structural Experiment, China Architecture \& Building Press, Beijing, China, 2008.

[33] N. K. Gosain, R. H. Brown, and J. O. Jirsa, "Shear requirement for load reversals on RC members," ASCE Journal of the Structural Division, vol. 103, no. 7, pp. 1461-1475, 1977. 
[34] Chinese national Standard, Code For Design of Concrete Structures (GB50010-2010), China Architecture Industry Press, Beijing, China, 2010.

[35] X. L. He, Study on the Seismic Response of RC Frame that Consider the Joint Shear Deformation, Master Dissertation, Chang'an University, Xi'an, Shaan xi, China, 2011.

[36] J. P. Fu, "Seismic behavior and design of joints in a reinforced concrete frame," Doctor Dissertation, Chongqing University, Chongqing, China, 2002.

[37] New Zealand Structural Design Code, Code For Design of Concrete Structures (NZS 3101-1), Standards Association of New Zealand, Wellington, New Zealand, 2006.

[38] Z. P. Bazant, "Physical model for steel corrosion in concrete sea structures-theory," ASCE Journal of the Structural Division, vol. 105, pp. 1137-1153, 1979.

[39] L. F. Ibarra, R. A. Medina, and H. Krawinkler, "Hysteretic models that incorporate strength and stiffness deterioration," Earthquake Engineering \& Structural Dynamics, vol. 34, no. 12, pp. 1489-1511, 2005.

[40] M. Rahnama and H. Krawinkler, "Effects of soft soil and hysteresis model on seismic demands," Research Report No.R108, Department of CEE, Stanford University, Stanford, CA, USA, 1993. 